\title{
Photometric Clot Detection
}

National Cancer Institute

\section{Source}

National Cancer Institute. Photometric Clot Detection. NCI Thesaurus. Code C111291.

A clot detection method that uses a photometric means (measuring the absorbancy of monochromatic light) to detect the presence and/or quantify the formation of a thrombus in a specimen. 